Regards sur l'économie allemande

Bulletin économique du CIRAC

$104 \mid 2012$

Varia

\title{
Société : les Allemands aiment confort et voyages
}

Isabelle Bourgeois

\section{CpenEdition}

\section{Journals}

Édition électronique

URL : http://journals.openedition.org/rea/4400

DOI : $10.4000 /$ rea. 4400

ISBN : 978-2-8218-1286-4

ISSN : 1965-0787

Éditeur

CIRAC

Édition imprimée

Date de publication : 13 avril 2012

Pagination : 33

ISSN : 1156-8992

Référence électronique

Isabelle Bourgeois, "Société : les Allemands aiment confort et voyages », Regards sur l'économie allemande [En ligne], 104 | avril 2012, mis en ligne le 17 avril 2012, consulté le 15 septembre 2020 URL : http://journals.openedition.org/rea/4400

Ce document a été généré automatiquement le 15 septembre 2020.

(C) CIRAC 


\title{
Société : les Allemands aiment confort et voyages
}

\author{
Isabelle Bourgeois
}

Interrogés sur leurs préférences en matière de dépenses, les Allemands placent en tête l'aménagement de leur intérieur (maison ou appartement) ; ils sont $55 \%$ à se dire prêts à dépenser beaucoup. En deuxième position vient la qualité de l'alimentation $(50 \%)$, suivie des voyages (44\%). C'est ce qu'il ressort d'un sondage, réalisé début mars auprès d'un échantillon représentatif de 20990 individus germanophones de plus de 14 ans, par l'Institut für Demoskopie d'Allensbach et publié à l'occasion de l'ouverture du Salon du tourisme de Berlin.

\section{Plus de la moitié partent une semaine}

2 S'ils goûtent de plus en plus les joies de la vie, les Allemands aiment toujours autant les voyages. Au cours des 12 derniers mois avant le sondage, plus de la moitié d'entre eux (56\%) avaient réalisé un voyage de 5 jours au moins. Quant au groupe cible que visent de plus en plus les professionnels du tourisme, à savoir les 50-69 ans, sa part de réponses s'élève à $61 \%$ - c'est autant que le groupe des 30-49 ans (62\%). Le critère déterminant reste le revenu, en Allemagne aussi: plus celui-ci est élevé, plus les Allemands voyagent. Ainsi, parmi ceux dont le revenu net mensuel est inférieur à $1750 €$, seulement $38 \%$ sont partis en voyage; dans la tranche des revenus supérieurs à $3500 €$, cette part s'élève à $72 \%$ (dans les 'classes moyennes', elle est de $57 \%$ ).

\section{Leur première destination : l'Allemagne}

3 Les destinations préférées des Allemands sont leur propre pays (27\%), puis l'Espagne ( $8 \%$ ), l'Italie et l'Autriche (ex aequo avec $7 \%$ ). Viennent ensuite la Turquie (5\%), les pays est-européens ( $4 \%$ ), la France, la Scandinavie et la Grèce (ex aequo avec $3 \%$ ). Les destinations plus lointaines (Afrique, Asie ou Amérique du Sud) sont nettement moins prisées ( $1 \%$ seulement). Il est intéressant de relever que les deux destinations 
historiques 'découvertes' par le tourisme de masse après l'adoption des congés pays en 1964 (Espagne et Italie) n'ont rien perdu de leur attractivité. A l'opposé, en l'espace de quelque 30 ans, l'Autriche et la France ont reculé. Si l'Allemagne a perdu 2 points depuis 1985, elle n'en reste pas moins de loin en tête, la mer (Baltique, $8 \%$, Mer du Nord, $6 \%$ ) et la montagne (Bavière, $7 \%$ ) se partageant les faveurs des touristes, suivies par la nouvelle capitale de l'Allemagne réunifiée, Berlin (3\%). Leur moyen de locomotion privilégié reste, on pouvait s'y attendre à voir le classement des destinations, l'automobile (61\%). Viennent ensuite l'avion, en nette hausse (44\% contre $22 \%$ en 1980$)$, le train, en recul (12\% contre $22 \%$ ) et l'autocar ( $12 \%$ contre $14 \%)$. IB

INDEX

Mots-clés : société, budget, consommation, sociologie, tourisme, groupe social, statistique 